\section{A toothbrush which looks as smart as it performs}

Philips Sonicare recently revealed a new flagship innovation: the DiamondClean Smart - dubbed the world's most intelligent toothbrush. The new brush uses unique connected technology to inspire and motivate patients to take better care of their oral health. It delivers exceptional oral care results by harnessing built-in smart sensor technology in both the toothbrush and brush heads and personalised coaching within the platform to help improve patients' brushing technique and ultimately achieve a healthier mouth. The new brush seamlessly syncs with the Philips Sonicare app, giving users real time data, feedback and guidance to empower them to proactively manage and improve their oral health.

DiamondClean Smart is smart in more ways than one - it also has dramatic bathroom appeal with its matt black handle, black brush head and charge-in-a-glass technology. The brush can also be charged using a computer USB to top up whilst travelling.

With over a century of healthcare expertise and 25 years in oral health care, Philips is committed to delivering complete and cutting-edge oral care solutions. With the Philips Sonicare new DiamondClean Smart and the complete oral care platform, Philips is empowering dental professionals and patients to make positive and transformative changes to their oral health.

Delegates to the BDIA Dental Showcase this autumn will be able to brush with the DiamondClean Smart for the first time. For further information on the latest Philips innovations visit www.philips.co.uk/ dentalprofessional or call 08000567222.

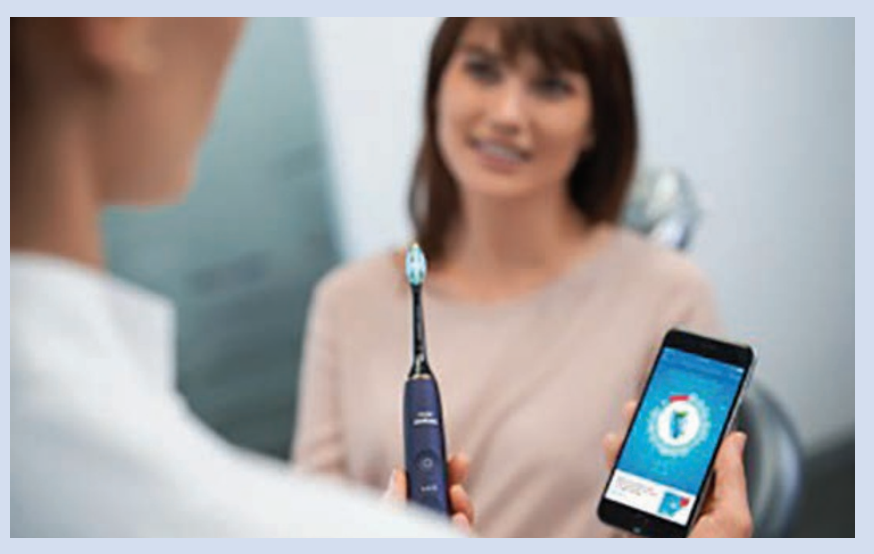

\section{Simple infection control solutions}

A new ecommerce service has been launched that bridges the gap between infection control and dental unit water systems (DUWS) for dental practices. DUWS can have problems with both bacteria growing in the water they use, as well as limescale preventing optimum performance.

Most suppliers of infection control products and services focus on eliminating the organic material (eg bacteria or legionella in extreme cases) found in dental practices, without necessarily looking at wider factors. By contrast, suppliers of DUWS, notably water purification equipment, focus on issues that arise from inorganic material that can affect water purity in DUWS (eg carbonates) and don't always appreciate how water purity and infection control need to work together to ensure HTM 01-05 compliance:

'Hard-water contamination (aka limescale) of wet instruments, which then go on to sterilization, can compromise the proper function of a small steam sterilizer...' HTM 01-05 sec 3.31

CleanCert specialise in providing simple infection control systems to remove any organic matter and infection control issues as well as those involving inorganic material and water purity. This co-ordinated approach helps with 'Best Practice' recommendations in HTM 01-05 and ensures your bacterial load on hard surfaces (TVC) and water quality levels (TDS) are reduced quickly, safely and cost-effectively.

www.cleancert.co.uk

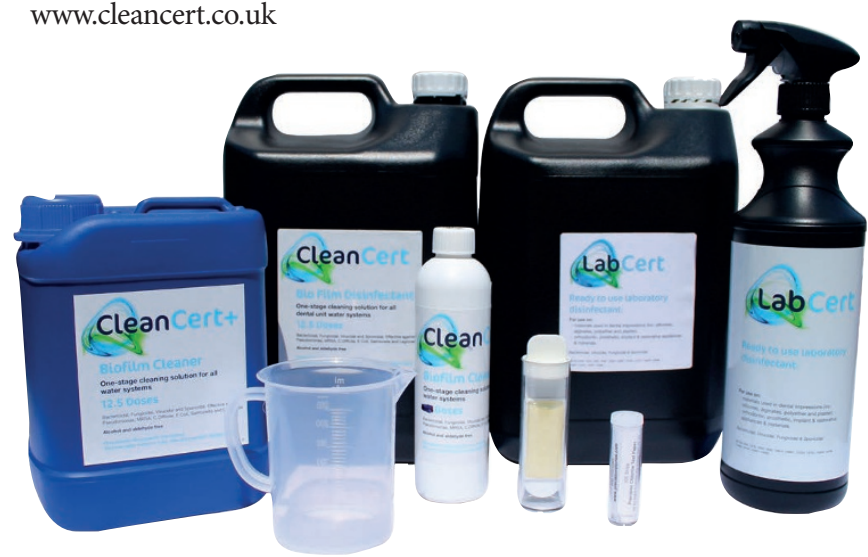

\section{Everything you need in vibrant colours}

Whether you're looking to simply inject a little personality into your practice, or you're striving to strengthen your brand, the Vibrenté range of dental consumables are the perfect option.

Available exclusively from Dental Express (a trading division of Surgery Express LLP), the range of bibs, aspirator tips, gloves, masks and more come in a wide range of vibrant, eye-catching colours.

Manufactured to the very highest standards, the range of Vibrenté products includes everything a dental practice needs to provide excellent, personalised service.

If you want your dental practice to stand out from the crowd, consider the Vibrenté range. Contact the expert team from Dental Express to find out more. Visit www.dental-express.co.uk, call 08007076212 or email web@dental-express.co.uk.
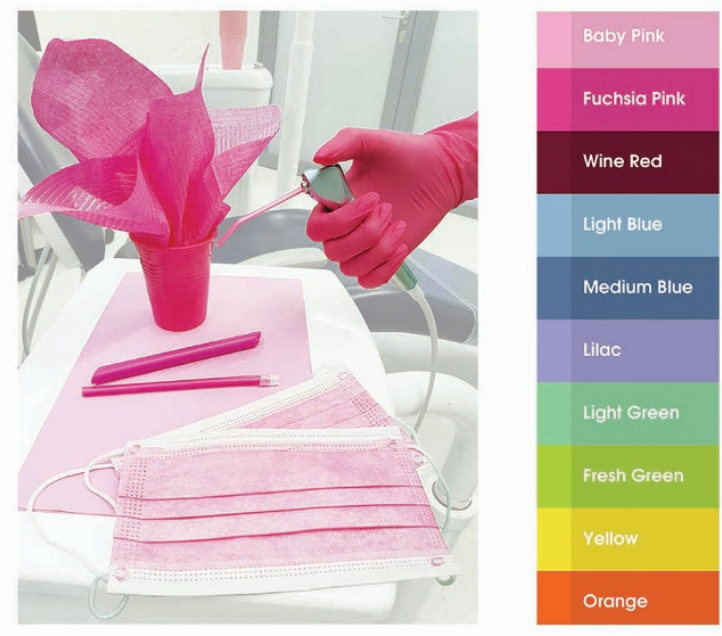